Eixo Roda, Belo Horizonte, v. 28, n. 4, p. 291-314, 2019

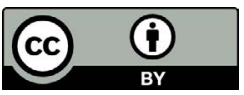

\title{
O riso unido ao distanciamento: correlações com o conto "Jacinto", de Alphonsus de Guimaraens, Cândido, ou o otimismo, de Voltaire e nuanças de um Alphonsus humorista em arquivos históricos
}

\section{The Laughter Coupled with Distancing: Interconnections with the Short Story "Jacinto" by Alphonsus de Guimaraens, the Candide: or Optimism by Voltaire and Nuances of an Alphonsus Humorist in Archives}

\author{
Danielle Fardin Fernandes \\ dfardin@gmail.com
}

Resumo: Este artigo trata do riso unido ao distanciamento, correlações com o conto "Jacinto (recordações de Vila Rica)", de Alphonsus de Guimaraens e o livro Cândido, ou o otimismo, de Voltaire, e também busca traçar um perfil humorista do poeta com base nos arquivos do Museu Casa Alphonsus Guimaraens. Ambos os autores, embora vivessem em países e épocas diferentes, de certo modo, acabaram se aproximando em suas escritas. Um, filósofo, dramaturgo e historiador, outro, poeta simbolista, se renderam aos artifícios da comicidade e produziram trabalhos que pertencem ao campo humorístico. No caso de Alphonsus, autor destacado neste trabalho, há uma personalidade que necessita ser delineada nesse sentido, uma vez que há uma grande quantidade de criações relacionadas ao riso nos manuscritos e outros documentos do Museu Casa Alphonsus Guimaraens, e todos, normalmente o conheciam como um poeta taciturno, o "solitário de Mariana". No geral este estudo busca investigar como Voltaire, em Cândido, ou o otimismo, e Alphonsus no conto "Jacinto (recordações de Vila Rica)", usam a ironia para provocar o riso, algo que, numa avaliação mais profunda, traduz uma decepção com o social e com a realidade existencial, gerando uma espécie de distanciamento. Pretende, por fim, com base em pesquisas em documentos 
históricos, encontrar uma lembrança dessa outra faceta de Alphonsus. O livro $O$ riso e o risivel: na história do pensamento, de Verena Alberti e o capítulo "Rabelais e a história do riso" em Cultura popular na idade média e no renascimento, de Mikhail Bakhtin, completam a investigação.

Palavras-chave: Alphonsus Guimaraens; museu; Voltaire; riso; Jacinto (recordações de Vila Rica; Cândido, ou o otimismo.

Abstract: This article deals with the laughter coupled with distancing, interconnections with the short story "Jacinto (recordações de Vila Rica)" by Alphonsus de Guimaraens and the book Candide: or optimism by Voltaire, also seeks to draw a humorous profile of the poet Alphonsus based on the archives of the Casa Alphonsus Guimaraens Museum. The two authors lived at different time but ended up approaching their writings. One was a philosopher, playwright and historian and the other was a symbolist poet and both surrendered to the comic and created works that are situated in the humorous field. There is an existence that needs to be delineated in this sense in the case of Alphonsus, the author highlighted in this work, since there is a great amount of creations related to laughter in the manuscripts and other documents of the Casa Alphonsus de Guimaraens Museum, and most of people knew him as a taciturn poet, the "solitary of Mariana". In general, this study seeks to investigate how Voltaire in Candide: or optimism and Alphonsus in "Jacinto (recordações de Vila Rica)" use an irony to provoke laughter, something that with a deeper evaluation translates a disappointment with social and existential reality generating a kind of detachment. Finally based on research in historical documents it seeks to find a memory of this other facet of Alphonsus. The book $O$ riso e o risivel: na história do pensamento, of Verena Alberti and the chapter "Rabelais and the history of laughter" in, Rabelais and his world of Mikhail Bakhtin, complete the investigation.

Keywords: Alphonsus Guimaraens; museum; Voltaire; laughter; Jacinto (recordações de Vila Rica; Cândido, ou o otimismo. 
Sua prosa [sobre Alphonsus] - a de comentarista dos acontecimentos - não é a do "alquimista da morte", mas de um homem culto, de olhos abertos para a vida, disposto a rir do que torna o homem ridículo.

José Algusto Guerra, Minas Gerais ${ }^{1}$

[...] o riso partilha, com entidades como o jogo, a arte, o inconsciente etc., o espaço do indizível, do impensado, necessário para que o pensamento sério se desprenda de seus limites.

Verena Alberti, O riso e o risivel

Existe uma quantidade notória de trabalhos no campo do humor, como cartas e descrições feitas em artigos sobre essa tendência ao riso em Alphonsus. O autor também, em certos casos, utilizava pseudônimos que permitiam a ele uma liberdade ainda maior para criar textos humorísticos. Esse contraste entre o poeta que se voltava para o luar, para os mistérios da morte e o irônico humorista, só é possível de ser entendido, com maior clareza, quando se vasculha os arquivos no Museu Casa Alphonsus Guimaraens. O livro Alphonsus Guimaraens no seu ambiente, escrito pelo próprio filho, contribui, em partes, para essa compreensão. $\mathrm{O}$ poeta trabalhava o riso de diversas formas, e ainda se sabe muito pouco sobre essas criações. No caso, o personagem Jacinto do conto de Alphonsus Guimaraens lembra um pouco o Cândido, de Voltaire. O conto foi extraído do livro Mendigos, uma reunião em prosa de histórias cômicas. Para a análise neste trabalho, o conto utilizado foi retirado da publicação Obras Completas, mas existe um volume único original no museu, datado de 1920, que não pode ser manuseado. $\mathrm{Na}$ época, essas prosas, e uma outra quantidade desconhecida de produções, eram utilizadas como fonte de renda do poeta, como é possível observar num anúncio do jornal $O$ Alfinete:

${ }^{1}$ GUERRA, José Augusto. A prosa alegre do pobre Alphonsus. Minas Gerais, Belo Horizonte, 9 jan. 1971, ano V. Suplemento literário n.228. p.6. 
Mendigos

Contos e chronicas

de Alphonsus de Guimaraens

$\mathrm{A}^{\mathrm{a}}$ venda na casa Mendes (Ouro

Preto), na Livraria Moraes

Marianna e nesta typographia

PREÇO ... . $\$ \$ 000^{2}$

(GUIMARAENS, 1921, p. 3)

No livro Cândido, ou o otimismo de Voltaire, a pureza expressa pelo personagem protagonista homônimo transforma a trama numa insistente ironia acerca de um "melhor dos mundos possíveis". Quem, na verdade, concebeu essa ideia foi um alemão, Gottfried Wilhelm Leibniz, criador da Teodiceia ${ }^{3}$ e filósofo, satirizado por Voltaire. Sua teoria demonstra que a maldade existe para que um bem (bonté) maior seja atingido. Neste caso, descreve o mundo como sendo perfeito, e, de acordo com esses princípios, as imperfeições, supostamente, existiriam como algo necessário para que os acontecimentos se processassem da "melhor maneira possível". As falhas, para ele, são importantes e completam a beleza das ações, como defensor do otimismo Leibniz dizia: "as sombras realçam as cores” (VOLTAIRE, 2012, p. 7). O personagem Cândido, embora aceite as ideias do mestre Pangloss, - personagem filósofo que divulga a teoria do "melhor dos mundos possíveis", e, possivelmente, um espectro de Leibniz - caçoa incessantemente dessa realidade otimista e critica os erros e perversidades do mundo. Para Cândido, as experiências

\footnotetext{
${ }^{2}$ A transcrição foi mantida no original com ajuda da então coordenadora do Museu Casa Alphonsus Guimaraens Ana Claudia Rolla Santos. No período de pesquisa, o museu estava passando por uma reestruturação. Muitos documentos não se apresentavam nas caixas porque estavam sendo reclassificados, e também não era possível saber exatamente que organização teriam. Aqui nessa superficial sondagem, então, não será possível citar a numeração correta onde foram encontradas informações sobre a personalidade humorística de Alphonsus. Serão mencionadas as datas e os nomes dos jornais, os tipos de manuscritos e o que for necessário para uma identificação precisa. ${ }^{3}$ Este livro foi escrito originalmente em francês Essais de Théodicée sur la bonté de Die, la liberté de l'homme et l'origine du mal (Ensaios de Teodiceia: sobre a bondade de Deus, a liberdade do homem e a origem do mal). Não cabe aqui discutir os princípios filosóficos de Leibniz. Este autor ficou conhecido por ser um polímata (estudioso de vários assuntos). Era do período Iluminista, e se destacou nos estudos matemáticos e filosóficos.
} 
vividas por seus amigos, por sua amada Cunegunda e por ele próprio, não condizem com um mundo perfeito e bom. A todo o momento, no livro, ele questiona o fato de ocorrerem desgraças, sobre si mesmo e sobre os outros personagens. Ele também ridiculariza aquele que pensa que por trás do horror experimentado há sempre algo de positivo, embora o livro apresente uma irônica visão otimista ao final.

Alphonsus de Guimaraens em seu conto "Jacinto (recordações de Vila Rica)", cujo personagem, assim como em Cândido, é título da história, busca satirizar os horrores possíveis oferecidos pelas experiências da vida, não contando sobre a própria vida, mas ultrajando a morte. Jacinto é um mendigo que, por imposição da igreja, acaba fornecendo parte da esmola para o ambicioso sacristão. Jacinto tem amigos, também mendigos, porém estes mesmos, em conjunto com o sacristão, terminam por tentar enterrá-lo vivo. Cometem tal ato, cada um, por um motivo específico.

Saliba, no início do livro Raízes do riso, busca algumas representações humorísticas que ajudam a entender o cômico na Belle Époque brasileira. Sobre este período, num sentido geral, ele diz: “[...] a Belle Époque representou um momento de crise e desarticulação desses dois sistemas de valores da dimensão cômica: a distinção entre o 'bom' e o 'mau' riso e a teoria da superioridade e do distanciamento" (SALIBA, 2002 p. 21). Segundo ele, estas são definições clássicas que foram quebradas pela própria condição de modernidade da Belle Époque. (SALIBA, 2002, p. 21) O clássico remete ao riso diretamente ligado à uma sensação de superioridade, onde é possível rir daquilo que é inferior, ou, no caso, "uma degradação do objeto risível e uma certa superioridade e distanciamento" (SALIBA, 2002, p. 20). Alphonsus Guimaraens e Voltaire criam nos textos em questão, tensões entre superioridade e degradação que colaboram para a definição do conceito de distanciamento. Saliba reforça essa ideia ao utilizar os exemplos de Pirandello quando menciona que a atitude cômica está para a superioridade e a humorística para a aproximação. Descreve, então, o caso da velha decrépita que se maquia para parecer mais nova, gerando uma situação ridícula. O esperado é que ela fosse uma senhora respeitável, mas o que ocorre é justamente o contrário. No caso, esta situação de quebra de expectativas provocaria o riso, antes pelo sentimento de superioridade; porém seria possível também que houvesse um reconhecimento, uma identificação - o outro se colocaria no lugar, e não numa situação superior (SALIBA, 2002, p. 24).

Em "Jacinto (recordações de Vila Rica)", o sacristão e outros mendigos, e em Cândido, ou o otimismo, o próprio Cândido e outros 
personagens são localizados, constantemente, entre as tensões do mundo superior e do mundo inferior. Há um choque entre os contrários: virtude/ defeito, perfeito/imperfeito, belo/feio etc. Nessas constantes dicotomias, aquilo que pertence a um plano de superioridade causa distanciamento. Os personagens, muitas vezes, se encontram em situações no plano superior, mas logo são destituídos de seus tronos e voltam para o inferior. Algumas vezes, o narrador situa os personagens num plano de superioridade criando ironia e ambientando o riso. A superioridade é a ocasião para o distanciamento, e, assim, ocorre um deslocamento constante entre o plano superior e inferior experimentado pelos personagens. O riso surge, muitas vezes, porque haverá algum tipo de degradação em relação superior. Em seus comportamentos experimentam algo que mascara a própria realidade. Tornam-se ridículos porque tentam ser bons, caridosos, puros etc. quando na verdade não são. $\mathrm{O}$ caso de Cândido torna-se mais complexo porque este tem consciência de seus atos, assim, ele se traveste propositalmente para escapar da realidade, pois ao se fantasiar de puro, através desse jogo com a ironia, critica a si mesmo e aos homens em geral. Os personagens de "Jacinto (recordações de Vila Rica)" não o fazem de modo proposital. São brutos, e agem, muitas vezes, por instinto e crueldade.

Em Cândido, ou o otimismo, Voltaire faz ataques às guerras, à intolerância, à igreja, à amizade etc. Em "Jacinto (recordações de Vila Rica)", o narrador critica aqueles que são considerados amigos, quando na verdade não o são e a bondade daqueles que trabalham para igreja, quando este sentimento, na verdade, não existe, há, apenas, o interesse. Em Cândido, ou o otimismo existe uma parte que se refere à igreja: quando os personagens chegam a uma cidade e se questionam sobre a beleza de um casal sentado num banco da praça. Cândido, então, se aproxima e descobre que se tratava de pessoas conhecidas: A moça Paquette, para sobreviver, se prostituía e o homem era um teatino que odiava o convento, e todo o dinheiro que arrecadava com os "maus sermões" (VOLTAIRE, 2012, p. 65), usava com as raparigas. De acordo com a proposta do autor, todos - uma generalização e possível interpretação - que estivessem intimamente ligados ao mundo sacerdotal viveriam cercados pelo "ciúme", pela "discórdia", palavras que saem da boca do próprio monge, Irmão Giroflée (VOLTAIRE, 2012, p. 65). Assim, os dois que antes, ao serem vistos de longe, pareciam um casal perfeito e belo, mostram o lado cruel da realidade. E Cândido, o personagem puro e alvo, acaba sendo, aos poucos, manchado pelo lodo das experiências reais descritas pelos que encontra no caminho de sua aventura. 
No conto, assim como no romance de Voltaire, há certa ilusão, certo idealismo partindo do narrador - no caso, Guy d'Alvim (pseudônimo de Alphonsus) é quem expressa esses sentimentos. Esse narrador-personagem conta a história de Jacinto, que além de mendigar costuma ser encontrado bêbado pelas sarjetas. É justamente num dia de porre que os outros mendigos, junto do sacristão, decidem enterrá-lo vivo, já que Jacinto encontra-se desmaiado. Guy d'Alvim ridiculariza Jacinto, o sacristão, os falsos amigos mendigos e o prático, que oficializa a suposta morte do protagonista a partir do atestado de óbito que emite. Este narrador-personagem nutre certo ideal pelos princípios de amizade e bondade, mas caçoa deles quando percebe que na realidade tais princípios seguem outro padrão. Assim, veremos aqui alguns trechos do livro de Voltaire e do conto de Alphonsus que nos levam a entender o riso provocado pela narrativa de Guy ou pelos diálogos de Cândido. Esses trechos também nos ajudarão a entender como o riso está relacionado à dicotomia ideal/realidade e como o princípio de pureza ou a alienação estão ligados ao riso como um distanciamento.

\section{Cândido, ou o otimismo e "Jacinto (recordações de Vila Rica)", o riso unido ao distanciamento e um Alphonsus humorista a partir de arquivos históricos}

Em Cândido, ou o otimismo, ${ }^{4}$ o protagonista passa por aventuras que, em grande parte, beiram o absurdo. O exagero nos acontecimentos

\footnotetext{
${ }^{4} \mathrm{Na}$ tradução aqui utilizada de Candide ou l'Optimisme, há uma nota explicativa sobre o uso da palavra "otimismo", assim diz: "Otimismo: De uso recente e especializado na França de então (apenas um uso registrado anteriormente ao Cândido, datado de 1737), o termo aparece apenas duas vezes no texto [no caso o original]. [...] A palavra não é empregada por Voltaire na acepção moderna de disposição psicológica, denotando antes uma opinião filosófica, exposta notavelmente por Gottfried Wilhelm Leibniz (1646-1715), a saber, que este mundo é o melhor dos mundos possíveis, porque Deus, sendo onisciente, deve conhecer todos os mundos possíveis; sendo onipotente, deve ser capaz de criar tudo o que quiser; e, sendo magnificente, deve escolher o melhor. O otimismo busca reconciliar a bondade e a perfeição divinas com a existência do mal. No entanto, ao asseverar a necessidade de as coisas permanecerem tais quais são, a palavra evoca o fatalismo. Em fevereiro de 1756, escreveu Voltaire a Elie Bertrand: "Necessitamos de um Deus que fale ao gênero humano. O otimismo é desesperador. É uma filosofia cruel com um nome reconfortante."
} 
contribui para a solidificação de uma comicidade contundente pautada na ironia. $\mathrm{O}$ autor produz esse efeito através de uma duplicidade constante entre um mundo superior e um mundo inferior. Logo no título do capítulo primeiro, onde se lê "Como Cândido foi criado num lindo castelo, e como foi expulso dele” (VOLTAIRE, 2012, p. 20), já se percebe a luta entre esses dois planos. O distanciamento está nessa necessidade de encontrar o mundo ideal ( $\kappa \alpha \lambda o ́ v)$. O lindo castelo pertence a um nível superior, e, ser expulso dele, é não fazer mais parte dessa perfeição.

Em "Jacinto (recordações de Vila Rica)", Alphonsus cria um personagem totalmente alienado, que acaba sendo vítima de sua própria estupidez. Sobre o protagonista, que de maneira sutil nos lembra Cândido e sua condição, o narrador diz o seguinte: "Filho das sarjetas, em má hora dado à luz por uma desgraçada como outra qualquer, criado sem amor e sem carícias, sem nunca ter conhecido a mentirosa infância dos bem-nascidos, estava satisfeito com a sorte." (GUIMARAENS, 1960, p. 410). Cândido tem sangue nobre, mas foi rejeitado pela mãe porque "essa senhorita nunca quis desposar" o pai, pois "o resto de sua árvore genealógica tinha se perdido pela injúria do tempo" (VOLTAIRE, 2012, p. 20), diferente de Jacinto que nunca conheceu a mentirosa infância dos bem-nascidos. A ironia é usada com muito mais intensidade no romance de Voltaire do que no conto de Guimaraens, o que suspende quase tudo que é expresso na história. Voltaire é agressivo em suas colocações, embora elas quase nunca estejam explícitas. Por exemplo, enquanto este associa o humano ao animal: "privilégio da espécie humana, como da espécie animal, servirse das pernas a seu bel-prazer" (VOLTAIRE, 2012, p. 22), Alphonsus mantém a ironia na superfície da narrativa e não se aprofunda na questão da natureza humana. Assim, quando Jacinto é levado para ser enterrado vivo por seus companheiros, dormindo, sonha com o inferno: "um lugar até certo ponto aprazível, divertido até" (GUIMARAENS, 1960, p. 412). Os dois personagens também apresentam um certo nível de alienação. Quase sempre não sabem o que acontece ao seu redor, se monstram distantes. "Cândido, completamente estupefato, não distinguia muito bem ainda como é que ele era um herói" (VOLTAIRE, 2012, p. 22), e a respeito de Jacinto "Embriagava-se, decerto, todos os dias; mas que tinha isto?" e "Já completamente transtornado, sem ideia de quem era e nem a que mundo viera, fixos os olhos nos pés, como que acompanhava os seus passos" (GUIMARAENS, 1960, p. 410-411). Muitas vezes, os personagens passam por uma relação com o nada, como uma espécie de fuga. 
No primeiro capítulo do livro O riso e o risível, Verena Alberti comenta as ideias de Ritter sobre a formação do riso. Sua constituição, segundo ela, é uma origem enigmática, já que está inserido em uma relação do nada com a existência (Dasein). Há nos costumes e nas características pessoais de cada ser humano uma inserção específica no campo da ordem e do sério - o que dá à definição sobre a natureza do riso um caráter ad infinitum. Mas está claro que se faz presente tanto naquilo que foi excluído quanto no que foi aceito pela existência. $\mathrm{Ou}$ seja, tudo que está fora da ordem e do sério é necessário ao ser, e, por sua importância, o não-oficial e não-sério estão sempre sendo motivo de reflexão nos estudos (ALBERTI, 1999, p. 11). Ela diz: "O riso é, portanto, a experiência do nada, do impossível, da morte - experiência indispensável para que o pensamento ultrapasse a si mesmo, para que nos lancemos no "não-conhecimento" (ALBERTI, 1999, p. 14). Não conhecer é se afastar, é se distanciar, é buscar desfazer essa ligação do homem com a realidade grotesca que o cerca.

Bakhtin utiliza o termo "realismo grotesco", que só pode ser compreendido no plano da cultura popular e da visão carnavalesca de mundo onde reside o que se entende como "baixo". Para explicar essa ideia, ele se apodera da imagem da velha grávida, que cria uma relação entre a morte e o nascimento. Quando, no caso, um desses dois polos é mutilado surgem os tipos cômicos (BAKHTIN, 1987, p. 45), ou as máscaras que circulam por esse ambiente que permitem duas reações: o afastamento ou a aproximação. Bakhtin encontra diversas definições sobre o riso investigando-o em épocas diferentes. Em uma dessas observações, ele diz que na Idade Média havia a possibilidade de se usar o riso como "válvula de escape", o que seria uma espécie de permissão para a manifestação da "segunda natureza do homem" (BAKHTIN, 1987, p. 65).

Outro autor, Battaille, entende que o riso era a causa e o objetivo primordial de seus próprios trabalhos. No campo filosófico, não há espaço para o cômico, pois o riso invalida o saber, mas de acordo com seus princípios era necessário que o não-saber fosse tratado com seriedade e a experiência do riso poderia levar a um conhecimento ainda mais profundo da questão (ALBERTI, 1999, p. 13). Rir pode ser entendido como um ato de distanciamento, uma maneira de se ver livre do sério, das preocupações. 
Nietzche, em uma das poucas observações sobre o riso, afirma que a verdade não pode ser considerada se não for acolhida por uma risada (ALBERTI, 1999, p.15). Para ele "ver naufragar as naturezas trágicas e ainda poder rir, apesar da mais profunda compreensão, da emoção e da compaixão, isto é divino" (ALBERTI, 1999, p. 22). Já Foucault, ao rir sobre as nomenclaturas de determinados seres em um texto de Borges, conclui que o riso se mostra para ele como um "não-lugar", onde o pensamento não poderia chegar, ou seja, na impossibilidade de relacionar a linguagem às coisas (ALBERTI, 1999. p. 16).

Rosset "situa o riso em um espaço para além do pensamento e da ordem - espaço que nosso pensamento e nossa linguagem não podem atingir" (ALBERTI, 1999, p. 21). O riso, para Freud, é uma forma de sair da razão e da crítica, e todo o processo que o origina permanece no plano do inconsciente (ALBERTI, 1999, p. 27). Assim, só é possível desvendar a estrutura do riso através dos conhecimentos simbólicos que cercam o indivíduo. O riso é uma espécie de crítica inconsciente. Todo esse processo de confrontamento interno sobre o mundo real não deve ser revelado para que o ato de rir não perca sua amplitude. E por assim ser, ocorre de modo irracional:

Falamos, é verdade, de 'fazer' um chiste, mas estamos cônscios da diferença (que se inscreve) em nosso comportamento quando fazemos um julgamento ou uma objeção. O chiste tem em alto grau a característica de ser uma noção que nos ocorre 'involuntariamente'. Não acontece que saibamos, um momento antes, que chiste vamos fazer, necessitando, apenas, vesti-lo em palavras. Temos, antes, um indefinível sentimento, cuja melhor comparação é com uma 'absence', um repentino relaxamento da tensão intelectual, e então, imediatamente, lá está o chiste - em regra, já vestido em palavras. (FREUD, 1996, p. 158)

Outra forma de observar o riso é quando, este, passa a ser uma maneira exagerada de se revelar a verdade, mas essa verdade torna-se uma aparência na medida em que pode ser encarada como uma representação social. A verdade passa a ser relativizada para que ocorra a desconstrução de algo. É o que acontece necessariamente com aquele tipo de trágico que retorna em forma de cômico. Aquilo que é mascarado socialmente emerge de modo tão intenso que, antes, o que era o horror passa a ser ignorado e transformado em riso. Assim, nesse contexto, o riso passa a 
ser uma maneira de revelar essa necessária verdade e ao mesmo tempo de nos refugiarmos dela. Alberti demonstra essas construções dizendo:

Em primeiro lugar a própria noção de riso trágico como afirmação do nada, do desaparecimento, do acaso, enfim, da destruição do sentido sem que nada seja dado em troca. Em segundo lugar, o fato de a oposição entre o riso trágico e o riso cômico (ou "clássico", como quer Rosset) não ser de modo algum linear ou transparente: o elogio daquele pode levar a uma exacerbação da verdade e da existência, compensando, sim, a cessação de ser com um sentido. (ALBERTI, 1999, p. 22)

Muitas vezes, o riso pode revelar uma espécie de realidade ainda mais complexa do que aquela que se apreende num primeiro plano. Quando se joga com o sentido das coisas, e, principalmente, quando o riso se transforma em arma; porque ele desestabiliza esse sério, ou o que entendemos por ordem, razão, justamente porque ele é uma atitude impensada e irracional - passa a combater uma realidade a priori para recriá-la, transformá-la em outra.

Ainda que Aristóteles não tenha feito um estudo sobre o riso, sua "influência talvez seja a mais marcante na história [...] principalmente no que concerne à consagração de sua definição do cômico como uma deformidade que não implica dor nem destruição.” (ALBERTI, 1999, p. 45). Suas contribuições nesse campo surgem com a Poética, onde busca definir a comédia e suas relações miméticas.

Joubert, por exemplo, formula um Tratado sobre o riso e o estuda enquanto ação biológica. O riso é provocado por dois órgãos: o cérebro e o coração. Neste tratado, o riso acaba sendo interpretado como uma ação voluntária; assim como o pulmão trabalha para a respiração humana através do comando do cérebro, o coração, também sob o comando do cérebro, trabalha para a elaboração do riso. Não é exatamente um ato racional e consciente, mas voluntário no sentido específico de vontade biológica. "Para Joubert, é justamente no ponto em que a razão ordena à faculdade motora que pare os movimentos da paixão que reside o problema do riso" (ALBERTI, 1999, p. 106).

Existem inúmeros estudiosos tais como Bakhtin, Deleuze, Le Goff, Bergson, Freud, Pirandello, etc. que deram espaço ao estudo do cômico; conhecer as perspectivas de cada época sobre o humor é tarefa que exige fôlego. Cada autor conduz a investigação sob uma determinada 
perspectiva, mas no geral, o riso está presente onde se estabelece o material humano. Bergson, por exemplo, diz: "não há comicidade fora daquilo que é propriamente humano. Uma paisagem pode ser bela, graciosa, sublime, insignificante ou feia; nunca será risível. Rimos de um animal, mas por termos surpreendido nele uma atividade humana ou uma expressão humana" (BERGSON, 2001, p. 2). Saber o que provoca o riso, por qual razão está diretamente ligado a questões particulares, ou como se estabelecem essas convenções, esclarece determinadas partes desse assunto; é um tema em constante transformação.

Platão em Filebo revela também certas funções do riso que ilustram essa perspectiva do distanciamento. Existem os prazeres verdadeiros e prazeres falsos. "Os prazeres verdadeiros são as belas formas, as belas cores, os belos sons e os belos perfumes, mas principalmente os prazeres do conhecimento". "Já os prazeres falsos são sempre afecções mistas. Não passam de uma cessação da dor e da reconstituição de nosso equilíbrio", (ALBERTI, 1999, p. 41). O riso se encontra no misto de prazer e dor. "É no contexto de caracterização das afecções mistas puramente espirituais" - divididas em três categorias: corporais, semicorporius e semi-espirituais e puramente espirituais - "que se dá a discussão sobre o riso: Sócrates quer provar, através da questão do cômico, que a afecção espiritual compõe-se de uma mistura de prazer e dor " (ALBERTI, 1999, p. 41). Mas há um problema na definição de riso estipulada em Filebo: Não se sabe se o riso é

na verdade, uma afecção da alma de estatuto equivalente às outras afecções, como a inveja, o amor, a cólera etc., ou se resulta de um "estado" de afecção da alma como o da afecção cômica. Parece-me que a passagem do Filebo dá margem a ambas as possibilidades, circunstância também responsável por sua complexidade. (ALBERTI,1999, p. 43)

Ainda em Filebo, Platão, através do diálogo entre três personalidades, no caso, Sócrates, Protarco e Filebo, usa um jogo de humor para conduzir os argumentos. Nele são discutidas as questãos do prazer ou inteligência como algo bom ( $\alpha \gamma \alpha \theta o ́ v)$ (PLATO, 2010, p. 16). Há entre eles uma disputa de quem sairá vencedor e conseguirá provar qual das duas faculdades é mais virtuosa. Há um trecho em que Sócrates diz: "E nosso estado de alma nas comédias? Não sabes que também aí ocorre um misto de prazeres e de dores?" (PLATÃO, [ca. 2017], p. 38). A 
comédia e a tragédia são postas em questão, e discorrendo sobre a inveja e o ridículo à que se sujeitam os homens vão demonstrando como são as amizades e por que os amigos riem uns dos outros. O ridículo está na natureza do ser que acha que é alguma coisa que não é. Nesse momento investiga-se a necessidade de rir. Mostra que o riso reina sobre os ricos que se julgam ser mais ricos do que realmente são, sábios que se julgam ser mais sábios etc. Rimos, portanto, de algo que aparenta ser o que na verdade não é (PLATÃO, [ca. 2017], p. 39). Segundo suas argumentações o fraco é objeto de riso porque é incapaz de se defender dos ataques, e por essa mesma condição é ridículo. Já os fortes são o que são porque se vingam e conservam sua natureza torpe. Continua o raciocínio afirmando que "alegrar-se com a desgraça do amigo [...] é produto da inveja" (PLATÃO, [ca. 2017], p. 40), sendo assim, conclui: “diz nosso argumento que ao misturarmos o prazer com a inveja, misturamos prazer com dor, pois há muito já admitimos que a inveja é dor da alma, e o riso, prazer, vindo ambos a reunir-se na presente conjuntura." (PLATÃO, [ca. 2017], p. 41). Bataille, no livro $A$ experiência interior, também não vê o riso como um sentimento positivo, segundo ele, "quando você ri você se percebe cúmplice de uma destruição daquilo que você é, você se confunde com esse vento de vida destruidora que conduz tudo sem compaixão até seu fim" (BATAILLE, 1992, p. 102). O riso, portanto, se confunde com a morte, e por assim ser, torna-se um sentimento trágico e conduz a uma análise destruidora daquilo que se ri.

Levando em consideração a personalidade de Alphonsus na intimidade, é possível dizer, partindo de um campo lógico, que o sentimento do riso circunda a positividade - em contraste à dor definida por Platão. Essa positividade - choque entre o sério e o não-sério seria uma maneira de transformar a realidade através da uma atividade que desmistificasse a aura que circunda determinada personalidade, justamente porque esta irá afastar-se de si mesma, se distanciar das tristezas humanas através de criações cômicas. Alphonsus de Guimaraens Filho fala um pouco sobre a intimidade de seu pai: "Quantas cartas em que buscavas pilheriar, refugiar-te no humorismo que foi tão teu, no jeito brincalhão de suavizar a realidade tormentosa." (FILHO, 1995, p. 48). Também em $O$ Alfinete, jornal de Mariana, há um pequeno artigo na capa em homenagem à morte do escritor. Diz assim sobre esta personalidade: 
Ele sabia compreender os deveres que lhe impunha o seu cargo magistrado, e sempre nelle se aviu com exemplar corretismo, mas conhecia também e sabia ensinar aos outros que a vida não é só feita para o choro ou para o lamento; que se deve separar um bocado dela, em que se esqueça a sua parte negra e se a encare como o é: fátua, vã, passageira, illusoria. Tanto assim que, apesar dos dissabores que as vicissitudes que ella lhe apresentava, sabia ele sorrir sempre. E era tão real o seu modo de viver, tão verdadeira a sua convicção, que logrou morrer sorrindo. (GUIMARAENS, 1921, p. 1)

O leitor acostumado a ler Alphonsus, notoriamente conhecido como poeta Simbolista e que se cercava das técnicas necessárias para produzir uma obra dessa mesma natureza, não supõe que teria tempo para desenvolver temas humorísticos. Contudo, sua obrigação com as metas de tiragens dos jornais para os quais trabalhava não o deixava se limitar à tendência dos poetas franceses da época. Esses trabalhos não eram menores que os que produzia como um autor do Simbolismo. Colaborou para os jornais Diário mercantil, Comércio de São Paulo, Conceição do Serro, Correio paulistano, O Estado de S. Paulo, A gazeta e revista FonFon!, tendo dirigido o Conceição do Serro, da cidade que hoje se chama Conceição do Mato Dentro. Em um trecho transcrito de uma carta do jornal A gazeta percebemos a importância de suas produções humorísticas:

O Dr. Adolpho Araújo, manda propor a V. Sa escrever para esta folha diariamente a seção humorística do Horácio que deixou lá dias pres... para Bello Horizonte. Pagam ... 160*000. Com avite esta proposta pedimos a V. Sa a bondade de comunicar-nos e começar a enviar os escriptos. Tem mais a $[\ldots]^{5}$

Alphonsus de Guimaraens filho relata as contribuições do pai para o jornal Conceição do Serro:

[...] recolhi umas charadas que fizeste para Conceição do Serro: no $\mathrm{n}^{\circ} 4$, de abril de 1904. E anunciei a existência de outras no $\mathrm{n}^{\circ} 6$, de 24 de abril deste ano, assinadas Old-Tom, como as anteriores. Old-Tom era pseudônimo com que firmavas muitos versos humorísticos do teu jornal. Mas há outras, assinadas Ritter

\footnotetext{
${ }^{5}$ Transcrição com falhas: colaboração de Ana Cláudia Rolla Santos. Documento: Carta enviada de São Paulo pelo jornal $A$ gazeta para Alphonsus de Guimaraens, na data de 12 de fevereiro de 1910; logomarca: A Gazeta, Rua 15 de Novembro, São Paulo.
} 
Brau (pseudônimo que usaste mais de uma vez), no n ${ }^{\circ}$. (FILHO, 1995, p. 239)

Essas são algumas registradas pelo filho, mas até mesmo Carlos Drummond de Andrade, sob o pseudônimo de Antônio Crispim, em artigo para a revista Leitura, já havia percebido essa tendência do poeta Simbolista, solitário de Mariana.

Percorrendo coleções de revistas velhas na Biblioteca Nacional, o repórter teve a atenção atraída por um certo João Ventania, que [de] um suposto Riacho do Vento, em Minas Gerais, mandava para o Fon-Fon! Poesias humorísticas ou satíricas. Riacho do Vento, não é lugar conhecido em Minas; e sua ligação com o evidente pseudônimo de João Ventania criava, em torno da personalidade, um ambiente. João Ventania fazia versos "diferentes", ao lado dos versos simplesmente marotos que o gênero lhe impuha. [...] Restava o trabalho de indentificá-lo. Não foi penoso. Lembrava-se o repórter de haver lido no Jornal das Letras, edição de outubro de 1949, uma reportagem de Aurélio Buarque de Holanda sôbre "Alphonsus de Guimaraens vivo". Aurélio fora a Mariana visitar a casa e o túmulo do poeta, e conversar com pessoas que o conheceram. E recolhera, entre outros pseudônimos de Alphonsus, o de João Ventania. Era o trocista do Fon-Fon! que se revelava. Alphonsus de Guimarãens Filho, a quem comunicamos o achado, reconheceu a autoria, quer pelo estilo, quer pela publicação de uma das poesias também em Conceição do Sérro. (ANDRADE, 1958, p. 23)

Dentro de casa também era uma pessoa um pouco diferente do que diziam. Em uma carta escrita para uma conhecida da família, Rosa Maria, ecoa a voz da esposa:

No primeiro pavimento da casa tinha o seu escritório e biblioteca onde costumava reunir-se com seus amigos para um bate-papo. Havia entre estes um espanhol e um padeiro com quem discutia e pilheriava. ${ }^{6}$

\footnotetext{
${ }^{6}$ Para identificação da carta fazemos as seguintes descrições: No topo há uma inscrição à caneta dizendo: Escrito para Rosa Maria, filha de Neguinha e Raul Costa. Maio/71. A carta está datilografada, tendo como título: Alphonsus na intimidade. Inicia-se assim: "A viúva do Poeta, minha tia-avó, falecida em julho de 1969, gostava de relatar à família como havia conheido do [erro] Dr. Alphonsus. Com sua voz serena e mansa dizia..."
} 
Há diversos relatos sobre a personalidade humorística de Alphonsus em seus arquivos no Museu Casa Alphonsus Guimaraens, além de uma quantidade expressiva de textos produzidos, e provavelmente desconhecidos, que se estendem pelos jornais da época. É nítido que essas produções estavam em comunicação com as tendências da época. "Jacinto" é apenas uma amostra da veia humorística existente neste poeta.

\section{Como ocorre o distanciamento em "Jacinto (recordações de Vila Rica)" de Alphonsus e em Cândido, ou o otimismo de Voltaire.}

No conto "Jacinto (recordações de Vila Rica)", Alphonsus ridiculariza o universo religioso construindo várias cenas em que demonstra um membro da igreja praticando atos que não condizem com o que se espera dessa estirpe. No caso, este personagem tem como objetivo básico satisfazer suas necessidades particulares. Seguindo um pensamento idealizado, o religioso teria que necessariamente ser bom e não mal; pensar no outro e não simploriamente em si mesmo. Enfim, o poeta Alphonsus sempre esteve envolvido em um ambiente de religiosidade - já dizia ele sobre sua terra: "cidade episcopal que dorme/No seio branco das litanias" (FILHO, 1995, p. 193) -, como se constata em inúmeros poemas, e suas relações próximas com as figuras religiosas da época, e por assim ser, talvez não se conformasse com a extrema importância dada pela igreja aos assuntos de cunho financeiro - observação natural dos espíritos mais críticos. No seguinte trecho o narrador comenta a função religiosa de Jacinto ao pedir esmolas para o sacristão:

Despertara às seis, preocupando-o ainda, como na véspera, a ideia última que o adormecera: o dia das esmolas. Sempre em aquele dia, saía Jacinto pelas ruas, de hábito branco, a pedir para a cêra da Senhora das Mercês; todos o conheciam e de longe as crianças lhe sorriam, acostumadas enfim à fealdade cômica das suas feições de mulato ruivo, nem preto nem branco. (GUIMARAENS, 1960, p. 410)

No geral, os personagens religiosos construídos nos contos, ou até mesmo nos poemas humorísticos, costumam estar ligados à figura do "interesseiro", do "avarento" ou do "falso bom homem". O dinheiro, a política, ou o estômago do religioso estão sempre em primeiro plano. 
No caso do conto, o sacristão, José Maria, junto com alguns amigos e um prático, resolvem executar um ato "caridoso": enterrar Jacinto depois que o encontraram desacordado no chão da sarjeta. Jacinto é um mendigo e está sempre bêbado. Sua fonte de renda vem das esmolas que arrecada, sendo que, uma parte, é forçosamente doada à igreja. Essa parte é entregue ao sacristão José Maria. Ainda assim o sacristão parece nutrir certo desprezo por Jacinto.

A bondade pura é questionada no conto. A bondade religiosa, dos amigos, do prático. No que se refere ao amigo mendigo de Jacinto, vemos esse falso sentimento de preocupação no seguinte trecho:

Feita a cova, rezaram-lhe alguns padres nossos por alma. Um dos amigos houve que até deu graças a Deus por ter acabado com Jacinto. Tinha promessa firme por parte do sacristão de ser ele quem daí em diante pediria esmolas para a ordem. (GUIMARAENS, 1960, p. 411)

Importante é saber que Jacinto não estava exatamente morto. Temos essa certeza quando lemos o seguinte trecho: "Um morto esquisito aquele: de vez em quando estremecia, roncava às vezes, fazendo o José Maria e os outros largarem-no assustados, para depois o carregarem de novo, tão quieto ficava" (GUIMARAENS, 1960, p. 411). O narrador brinca com leitor buscando criar uma dúvida sobre essa morte. Jacinto está realmente morto? Se está, por que ronca então? Se não está morto por que seus amigos mendigos, o sacristão José Maria e o prático acreditam que está? Por que querem enterrá-lo vivo? Isso não seria um ato assustador? Neste conto, muitas perguntas surgem diante do leitor e a ironia dessa incompreensível morte é reforçada a cada parágrafo. Jacinto dorme devido a embriaguez, mas o narrador brinca com os que ouvem "esse caso extraordinário" (GUIMARAENS, 1960, p. 410), como é dito pelo próprio narrador-personagem, Guy d'Alvim, ao dizer "um morto esquisito aquele" (GUIMARAENS, 1960, p. 411). Qualquer um poderia realmente omitir de si mesmo essa informação, como o próprio narrador o faz, através de uma construção irônica. O narrador não pretende ser sincero. Ele também não se considera sério. E questiona o mundo, levantando dúvidas através da narrativa: o que pode ser sério diante dessas possibilidades sarcásticas de amizade, fidelidade, compaixão, respeito? Se visivelmente ele dorme, qual a razão de dá-lo como morto? O poeta simbolista taciturno e solitário não pensa que a morte seja uma 
brincadeira, mas a outra faceta de Alphonsus pode encontrar humor, já que está mais próxima de um homem comum. O homem popular ri dessa situação, porque, na mentalidade deste homem inculto a morte é algo que simplesmente faz parte do cotidiano.

Ao final do conto, o leitor entende que, na verdade, Jacinto estava completamente desmaiado devido à uma bebedeira de costume. Ele sonha estar no inferno, e acorda atordoado à beira da cova aberta por seus companheiros - ao descobrir que não havia nada para beber no inferno.

Achava-se agora no inferno, não aquele que imaginara em tempos de infância, - uma enorme cozinha onde os satanases assavam, em caldeirões vermelhos, milhões de danados, deixando-os sentir supliciosamente os ósculos de fogo das labaredas delgadas, finas como línguas [...]. Dirigiu-se a um homem de chifres e pés de bode, que oferecia, em um vaso de uso privado, excremento aos hóspedes. - A sua graça? - Belfegor, para o sevir. - Obrigado. Pode dar-me um pouco de água? $\mathrm{O}$ diabo soltou uma risada atroz [...] Ali não havia água [...] - E cerveja? e vinho? e restilo? Nada absolutamente. Como viver no inferno então? (GUIMARAENS, 1960, p. 412)

Jacinto descobre, então, ao acordar, que não seria enterrado como gostaria. Na voz do narrador, o dilema se torna mais evidente: "Sempre pensara que iria amortalhado na estamenha branca das esmolas" (GUIMARAENS, 1960, p. 412). Ou pelas próprias palavras de Jacinto, "E não é que ele [o sacristão] me ia enterrar sem o hábito?" (GUIMARAENS, 1960, p. 412). Jacinto queria ser enterrado com o hábito, mas o sacristão não havia se preocupado com esse detalhe, o que demonstra um total desrespeito com o suposto defunto. Além de ser enterrado vivo, ainda o seria sem o hábito que lhe fora prometido.

Os personagens tanto do conto "Jacinto (recordações de Vila Rica)" quanto em Cândido, ou o otimismo são puros e, de certo modo, fieis à realidade que os condena. São personagens irreverentes e que não escondem sua verdadeira natureza. Voltaire criou seu protagonista como uma crítica ao provincianismo da época. O autor, em seus textos literários, procurava associar as reflexões que fazia enquanto filósofo às vivências de seus personagens. Era ótimo, também, em criar inimizades, tanto que, muitas vezes, foi obrigado a abandonar os círculos de amizade e locais onde residia. Cândido foi elaborado no auge de suas atividades e, por isso, é um personagem tão bem estruturado. Anarrativa 
é extremamente apurada contendo críticas certeiras. Há uma passagem em que o protagonista se reconhece como o melhor homem do mundo, ao matar o irmão de Cunegunda: "'Que tristeza! Meu Deus', disse ele, 'matei o meu antigo mestre, o meu amigo, o meu cunhado; sou o melhor homem do mundo, e eis aí já três homens que eu mato; e, entre esses três, há dois padres"' (VOLTAIRE, 2012, p. 42). O narrador costura em suas frases essa ironia desconcertante, descendo até as tristes vilezas da natureza humana e elevando-as até às mais sublimes compreensões dela mesma.

Definir bem e mal não é o que pretende o estudo, uma vez que tais definições poderiam tender a um universo de julgamentos. Bakhtin cita Demócrito no seguinte trecho, o que ajuda a entender por que Voltaire e Alphonsus deram a esses personagens características contraditórias como buscar praticar o bem quando na verdade praticam o mal, serem amigos quando na verdade são inimigos etc. - e trabalharem com eles a partir da ironia, fazendo com que o leitor ria das desgraças vividas pelos personagens.

No Romance de Hipócrates, o riso de Demócrito exprime uma concepção filosófica do mundo, ele tem como objetivo a vida humana e todos os vãos terrores, as vãs esperanças do homem em relação aos deuses e à vida além-túmulo. Demócrito definiu o riso como uma visão unitária do mundo, uma espécie de instituição espiritual do homem que adquire sua maturidade e desperta. (BAKHTIN, 1987, p. 58)

Uma forma de se desligar da realidade, mas ao mesmo tempo não se ver totalmente livre dela; mesmo porque, talvez, o excesso de reflexão possa levar ao riso, ou até mesmo, quando a verdade é tão evidente e imutável que não há nada a se fazer a não ser rir.

Partindo do princípio de Aristóteles de que "o homem é o único ser vivente que ri" (BAKHTIN, 1987, p. 59), Ronsard, em sua poesia dedicada a Belleau (Oeuvres, Ed. Lemerre, t. V, 10), escreve um poema que ilustra essa questão da capacidade racional do homem e o insere no mundo como um ser pensante, movido pelos anseios do sério e do intelectual. 
Deus, que ao homem submeteu o mundo,

Ao homem apenas concedeu o riso

Para que se divertisse, e não às bestas

Que não têm razão nem espírito nas cabeças

(BAKHTIN, 1987, p. 59)

Assim, temos o homem como diferente dos outros seres viventes pela condição do riso, sua capacidade crítica, por sua razão. Alphonsus nos mostra no conto "Jacinto (recordações de Vila Rica)" o que entende sobre o ser humano e a vida na terra, ideia esta que não deixa de coincidir com a crítica voltairiana. O narrador descreve, que, enquanto Jacinto estava dormindo à beira da cova - local onde logo seria enterrado por seus amigos - acaba tendo um sonho: uma hora no paraíso, outra no inferno. Uma parte intensamente cômica se faz na descrição do inferno:

[...] um lugar até certo ponto aprazível, divertido até, pois que os diabos eram de um cômico irresistível, com caras de cabras uns, outros iguais aos macacos, outros ainda do feitio dos sapos, de lunetas, charuto na boca, o ar gentil.

Não era a mansão maldita das lágrimas, onde só há ranger de dentes e convulsões de dolorosas agonias; o pobre rapaz [referindo-se a Jacinto] não podia ter visões dantescas, e a sua alma sem ideal não poderia evocar os sete círculos fatais. (GUIMARAENS, 1960, p. 412)

A ignorância passa a ser uma virtude no personagem Jacinto, dando a ele acesso livre ao mundo. Brinca ainda com um cânone literário (quando se lê visões dantestas no trecho acima), e, reduzindo $\mathrm{o}$ acontecimento à materialidade do ridículo, ajuda a aliviar um pouco o peso da impossibilidade de atingir a grandiosidade dos escritos de Dante Alighieri em A Divina Comédia. O lugar onde Jacinto mais se sentia confortável era mesmo na terra. Quando o narrador faz uma referência sobre sua alma diz: "sem ideal" (GUIMARAENS, 1960, p. 412). Importante ressaltar que a terra é lugar onde todas as desgraças se revelam para o homem intelectual, racional, pensante, não para o homem comum, popular, inculto. Como Jacinto era um homem do povo não poderia conhecer o inferno "dantesco", que, segundo Guy d'Alvim, era muito mais terrível, muito mais doloroso.

Em Cândido, ou o otimismo de Voltaire, o mundo se processa de modo muito parecido com este criado por Alphonsus em "Jacinto 
(recoradações de Vila Rica)". Como é o "melhor dos mundos possíveis", de acordo com o dr. Pangloss, o personagem Cândido "que tinha sido educado para nunca julgar nada por si mesmo" (VOLTAIRE, 2012, p. 67) passa a discutir com um senador a respeito das grandes obras de Homero, Virgílio, Cícero, Milton etc. O senador Pococuranté menospreza os clássicos e deixa Cândido um pouco perturbado porque, afinal, ele "respeitava Homero, gostava um pouco de Milton" (VOLTAIRE, 2012, p. 68). Mas a personalidade de Cândido mostrava o quão desprovido de crítica, o quão transitório, volúvel e apático ele era, porque em outro momento ele põe-se a elogiar o senador "- Oh, que homem superior! [...] - Que grande gênio esse Pococuranté!" (VOLTAIRE, 2012, p. 69). Porém, essa inocência demonstrada, não é senão uma forma do narrador de criticar ao extremo, de ridicularizar, de ironizar o homem e as vicissitudes. Assim, Cândido termina a frase dizendo: "Nada pode lhe agradar!" (VOLTAIRE, 2012, p. 69). A genialidade, então, vem de excessivo mau humor, ou de radicalismo.

Com Guy d'Alvim lembramos um pouco essa ofensividade irônica. Para criticar os homens e suas deformações espirituais, o narrador afirma que o inferno é a convivência terrena, é a própria vida na terra. Essa afirmação se confirma no trecho em que Jacinto sonha com o inferno que não era exatamente dantesco, no qual Guy reforça: "Assim, diante de tão inesperado quadro, Jacinto sossegou: continuaria no inferno a vida que levava na terra, sempre cercado de homens que eram mais selvagens do que os diabos presentes, tão corteses e pândegos." (GUIMARAENS, 1960, p. 412).

Ainda sobre o gênio do senador Pococuranté, Voltaire procura rebaixar a natureza humana através dos comentários "puros" de Cândido. Como quando Cândido elogia o jardim do senador e este diz que nunca havia visto "nada de tão mau gosto" (VOLTAIRE, 2012, p. 69). Por fim, para encerrar a conversa, Cândido diz a Martinho: "haveis de convir que é o mais feliz de todos os homens, pois está acima de tudo que possui" (VOLTAIRE, 2012, p. 69). Assim como o "melhor dos mundos possíveis" é a vida na terra, "o mais feliz dos homens" é aquele que mais possui e o que menos dá valor ao que tem. Assim, o homem erudito, aquele que leu as grandes obras, sente-se acima delas e de tudo. Estar acima de tudo é resolver o mundo e torná-lo insignificante. Ser sábio é chegar ao ponto de pensar que tudo é desprezível porque o mundo foi purificado e divinizado. Cândido não vê o mundo com esses olhos. Como ele não sabe nada, não diviniza, não pensa, e essa suposta ingenuidade, usada como arma para 
atacar essa superioridade, o torna puro completamente, o distancia. A vida terrena passa a ser a única verdade. Mas o personagem Cândido abusa dessas questões. Ele deixa de pensar e é naturalmente conduzido pelas situações. Segue seu curso sem muitos rodeios ou reflexões. Uma metáfora do homem cotidiano. Um homem cândido, candide no original francês, como quer o autor.

Interessante é que Jacinto encontra sua pureza na vida mundana, terrena, e Cândido, ao se colocar como um inocente fazendo comentários irreverentes sobre os defeitos espirituais humanos parece não aceitar a vida limitada, sofrida, defeituosa. Cândido vê o inferno na vida, e, por isso, não deixa de fazer suas observações, ainda que isso não mude radicalmente sua condição.

\section{Conclusão}

Tanto Cândido quanto Jacinto são personagens que questionam essa forma de vida puritana e se inserem num mundo repleto de tristezas, desgraças, injustiças e vulgaridades; questionam a aparências das relações sociais e buscam uma verdade essencial ao criticarem, de modo articulado, a natureza humana. Um, filósofo, dramaturgo e historiador; o outro, poeta Simbolista demonstram conhecimentos distintos quando se trata de ironia e humor. Como o cômico não é a corrente condutora dos escritos de Alphonsus - o que não a torna menos complexa - mas é exacerbada em Voltaire, o rítimo de ataques é completamente diferente. Explorados de forma superficial neste artigo sobre os escritos que provocam riso, faz-se possível formular algumas considerações: criar uma espécie de moral, refletir sobre a condição humana, atacar ideias específicas e tipos humanos etc., ou seja, há inúmeras especulações possíveis. Duarte tem o seguinte pensamento ao analisar "Missa do galo" de Machado de Assis: "o artista passa a tentar expressar de maneira indireta a sua inquietação diante da alienação do indivíduo numa sociedade que procura ignorá-lo em sua natureza, desejos e necessidades." (DUARTE, 2006, p. 155). Duarte, ainda, ao analisar as ideias de Schopenhauer, afirma que quando se brinca diante de algo sério produzimos ironia, mas quando cuidamos dessas brincadeiras com seriedade produzimos humor. E somente os antigos eram mestres da ironia justamente pela própria condição de ataque generalizado que lhes era natural (DUARTE, 2006, p. 154). Alphonsus em seus poemas e prosas manifestava esse outro lado, que a maioria 
dos escritores preferem esconder. Essas nuanças estão escondidas nas esquecidas edições de jornais que recebiam, através de pseudônimos sua máscara para difundir um novo escritor -, cartas e outros materiais. Como as suas produções eram constantes e necessárias, não seria muito absurdo dizer que, talvez, ele fosse um exímio humorista - não cabe a este estudo criar este conceito, mas é possível que haja uma quantidade ainda maior de criações dessa natureza.

No livro de Voltaire e no conto de Alphonsus, questionamentos de natureza filosófica são traçados como parte de um conjunto complexo que ridiculariza o humano. É possível entender que Alphonsus e Voltaire exageraram as crueldades vividas e praticadas por seus personagens para demonstrar a que está sujeito o humano e, deste modo, ao ultrapassarem essa medida, acabaram transformando aquilo que, antes seria motivo de choro, e, contudo, foi revertido em riso. Cândido e Jacinto tanto vivem a desgraça quanto a ridicularizam, assim não precisam necessariamente encará-la de frente.

\section{Referências}

ALBERTI, Verena. O riso e o risível: na história do pensamento. Rio de Janeiro: Jorge Zahar Ed, 1999. (Coleção Antropologia Social).

ANDRADE, Carlos Drummond de. João Ventania: um dos lados de Alphonsus de Guimaraens. Leitura: a revista dos melhores escritores, Rio de Janeiro, ano 16, n. 7, p. 23-24, jan. 1958.

BAKHTIN, Mikhail. Cultura popular na Idade Média e no Renascimento: o contexto de François Rabelais. Tradução de Yara Frateschi Vieira. São Paulo: HUCITEC; Brasília: Editora da Universidade de Brasília, 1987.

BATAILLE, Georges. A experiência interior. Tradução de Celso L. Coutinho et al. São Paulo: Ática, 1992.

BERGSON, Henri. O Riso: ensaio sobre a significação da comicidade. Tradução de Ivone Castilho Benedetti. São Paulo: Martins Fontes, 2001. (Coleção Tópicos)

DUARTE, Lélia Parreira. "Missa do galo": ironia romântica, humor e leveza. In:__. Ironia e humor na literatura. Belo Horizonte: Editora PUC Minas; São Paulo: Alameda, 2006. 
FILHO, Alphonsus de Guimaraens. Alphonsus de Guimaraens no seu ambiente. Rio de Janeiro: Fundação Biblioteca Nacional, Dep. Nacional do Livro, 1995.

FREUD, Sigmund; STRACHEY, James; FREUD, Anna. Parte teórica: a relação dos chistes com os sonhos e o inconsciente. In: Edição standard brasileira das obras psicológicas completas de $\overline{\text { Sigmun }} d$ Freud: Os chistes e a sua relação com o inconsciente. Tradução de José Luiz Meurer. Rio de Janeiro: Imago, 1996. v. 8.

GUIMARAENS, Alphonsus de. Jacinto. In: . Obra completa. Rio de Janeiro: José Aguilar, 1960. (Biblioteca Luso-Brasileira. Serie Brasileira)

GUIMARAENS, Alphonsus de. O Alfinete: Periódico crítico, humorístico, imparcial e independente, Mariana, capa, p. 1, 3 ago. 1921.

LEIBNIZ, G. W. Theodicy: Essays on the Goodness of God, the Freedom of Man and the Origin of Evil. Tradução de E. M. Huggard. London: Routledge \& Kegan Paul Limited, 1951. Disponível em: http://www. philvaz.com/apologetics/LeibnizBestPossibleWorldTheodicy.pdf. Acesso em: 27 abr. 2019.

PLATÃO. Filebo, [S.l.]: Grupo de Discussão Acrópolis, [ca. 2017]. Tradução de Carlos Alberto Nunes. Disponível em: http://lelivros.love/ book/download-filebo-o-prazer-a-vida-boa-platao-em-epub-mobi-e-pdf/. Acesso em: 17 dez. 2018. Livro de domínio público.

PLATO. Philebus. Tradução de Kyriakos Zambas. Projeto Gutenberg, 2010. Disponível em: https://www.gutenberg.org/ebooks/31436. Acesso em: 25 nov. 2018.

SALIBA, Elias Thomé. Prólogo: O humor como forma de representação na história brasileira. In: - Raízes do riso: a representação humorística na história brasileira-da Belle Époque aos primeiros tempos do rádio. São Paulo: Companhia das Letras, 2002.

VOLTAIRE. Cândido, ou o otimismo. Tradução de Mário Laranjeira. São Paulo: Penguin Classics Companhia das Letras, 2012.

Recebido em: $1^{\text {o }}$ de maio de 2019. Aprovado em: 4 de setembro de 2019. 